ARTICLE

https://doi.org/10.1057/s41599-019-0319-5

\title{
CRISPR in context: towards a socially responsible debate on embryo editing
}

\author{
Michael Morrison (10 ${ }^{1,3 \star} \&$ Stevienna de Saille ${ }^{2,3 \star}$
}

\begin{abstract}
Following the birth in 2018 of two babies from embryos altered using CRISPRCas9, human germline gene editing (GGE) moved from abstract concern to reality. He Jiankui, the scientist responsible, has been roundly condemned by most scientific, legal and ethical commentators. However, opinions remain divided on whether GGE could be acceptably used in the future, and how, or if it should be prohibited entirely. The many reviews, summits, positions statements and high-level meetings that have accompanied the emergence of CRISPR technology acknowledge this, calling for greater public engagement to help reach a consensus on how to proceed. These calls are laudable but far from unproblematic. Consensus is not only hugely challenging to reach, but difficult to measure and to know when it might be achieved. Engagement is clearly desirable, but engagement strategies need to avoid the limitations of previous encounters between publics and biotechnology. Here we set CRISPR in the context of the biotechnology and fertility industries to illustrate the lessons to be learned. In particular we demonstrate the importance of avoiding a 'deficit mode' in which resistance is attributed to a lack of public understanding of science, addressing the separation of technical safety criteria from ethical and social matters, and ensuring the scope of the debate includes the political-economic context in which science is conducted and new products and services are brought to market. Through this history, we draw on Mary Douglas' classic anthropological notion of 'matter out of place' to explain why biotechnologies evoke feelings of unease and anxiety, and recommend this as a model for rehabilitating lay apprehension about novel biological technologies as legitimate matters of concern in future engagement exercises about GGE.
\end{abstract}

\footnotetext{
${ }^{1}$ Faculty of Law, University of Oxford, Ewert House, Banbury Road, Oxfordshire, Oxford OX2 7DD, UK. ${ }^{2}$ Institute for the Study of the Human (iHuman), Dept of Sociological Studies, The University of Sheffield, ICOSS, 219 Portobello, Sheffield S1 4DP, UK. ${ }^{3}$ These authors contributed equally: Michael Morrison, Stevienna de Saille *email: michael.morrison@law.ox.ac.uk; s.desaille@sheffield.ac.uk
} 


\section{Introduction}

n 25 November 2018, on the eve of a major scientific summit in Hong Kong, a Chinese scientist named $\mathrm{He}$ Jiankui made a startling announcement: as a result of experiments conducted at his clinic, the world's first genetically edited babies had been born (Regalado, 2018b).

The news was tumultuous and unexpected. Deliberately making permanent, heritable changes to the genes of a human embryo and implanting it with the intent to establish a pregnancy has long represented a moral boundary, one that is prohibited in a number of countries, including the US (Araki and Ishii, 2014). The announcement was unexpected not because the technical possibility itself was unanticipated-techniques to alter the genetic material of living cells have been around since the 1970s, and scientists have long expected they could one day be used for this purpose-but because human applications have remained limited due to concerns about safety and efficacy, even as modification of bacteria, plants and animals has become routine.

The discovery in 2012 of a system known as CRISPR (Clustered Regularly Interspaced Short Palindromic Repeats) has now substantially changed the field. CRISPR utilises a natural function of bacteria, which is faster, cheaper and easier to use than earlier techniques to target and change DNA. Such technologies are sometimes described as 'foundational' or 'gateway' because they have broad application and offer advances over existing practices, resulting in rapid, far-reaching adoption across a range of sectors (Feeney et al., 2018). By 2017 papers describing experiments using CRISPR-Cas9 (Cas9 being a protein 'scissors') were triple those of earlier techniques combined. ${ }^{1}$

The potential for CRISPR and similar tools to make inheritable changes to human embryos, known as germline genome editing (GGE), is particularly challenging to regulate at the global level. Where human clinical applications of somatic (non-heritable) genome editing must proceed through a framework of costbenefit analysis, clinical trials and regulatory review prior to any marketing approval (Nicol et al., 2017), germline modifications are already being framed as an assisted reproduction technology (ART). Fertility services, which allow evaluation and selection of embryos bearing certain characteristics, including preimplantation genetic diagnosis and in some countries sex selection, are already provided through an array of largely private clinics in countries around the world (Spar, 2006; Whittaker, 2011) and some scientists (including $\mathrm{He}$ ) have already indicated interest in opening IVF clinics specialising in embryo editing (Begley, 2019; Cohen, 2019).

Some jurisdictions, such as the UK, take a 'strict but permissive' approach with stringent oversight from a national regulatory body, in this case the Human Fertilisation and Embryology Authority (HFEA). At the international level, however, the institutions, extent, and substance of regulation varies considerably between jurisdictions, depending on their resources, culture, legal framework, style of government and prevailing morality (Araki and Ishii, 2014; Roseman et al., 2019). This raises the very real possibility of GGE being incorporated into the existing phenomenon of 'reproductive tourism' where people cross national borders in search of assisted reproductive services, such as surrogacy or the use of anonymous donor gametes, that are not permitted in their own country (Roseman et al., 2019). The difficulty of regulating untested and unproven medical interventions at the global scale has also previously been demonstrated with the growth of the private stem cell treatment industry (Petersen et al., 2017).

Recognising both the ethical issues and the rapidity with which the field was expanding, two of the scientists on the original CRISPR discovery team, Jennifer Doudna and Emmanuelle
Charpentier, published a review paper in Science in which they concluded that:

The era of straightforward genome editing raises ethical questions that will need to be addressed by scientists and society at large. How can we use this powerful tool in such a way as to ensure maximum benefit while minimising risks? It will be imperative that nonscientists understand the basics of this technology sufficiently well to facilitate rational public discourse. Regulatory agencies will also need to consider how best to foster responsible use of CRISPR-Cas9 technology without inhibiting appropriate research and development. (Doudna and Charpentier, 2014, pp. 1258096-7).

He Jiankui's revelation has added impetus and urgency to these questions, not so much because of what he did, but when. A number of prominent scientists have argued that there can be instances where editing the genome of an embryo may be not only ethical, but a moral obligation if a child would otherwise be born with a serious disease (Baltimore et al., 2015). However, He proceeded with his experiment before any general agreement that the science or the public were ready for this step. Several prominent CRISPR scientists have now issued calls for a global moratorium on editing embryos (Lander et al., 2019), ${ }^{2}$ while others insist that He's experiment, although badly done, shows that GGE is ready to move ahead with more rigorous, ethical oversight in place (Cohen, 2018), but calls for public dialogue to 'create a societal consensus' form the basis of legitimacy for both sides of the argument (Rosemann et al., 2019). Thus, a number of critical questions remain unanswered, even unasked.

Although the call for societal engagement is laudable, we argue it also requires careful examination. Despite the massive press coverage of He's announcement, there has so far been no major public protest about GGE, such as those that accompanied gene patenting (Parthasarathy, 2017), GM crops in Europe (Jasanoff, 2011) or recent plans to release genetically modified mosquitos in Florida (Mole, 2016). Moreover, survey after survey indicates that people are generally supportive of somatic (i.e., non-reproductive) genome editing, only somewhat supportive of editing which can be passed to future generations, and overwhelmingly against editing for non-medical reasons (see, for example, Hendriks et al., 2018; Lawton, 2018; Michie and Allyse, 2019; Pew, 2016; Wipperman and Campos, 2016). From this, one might even argue that the public's consensus position is already clear.

In order to understand why the call for consensus on GGE is still repeated by prominent scientists, clinicians and academics, we need to consider CRISPR in context. This means looking at GGE in light of the history and organisation of biotechnology, and of assisted reproductive technologies (ART), rather than viewing the 'CRISPR babies' as an isolated aberration. As we shall discuss, setting GGE in the broader context of biotechnological innovation reveals serious flaws in simplistic calls for dialogue, and highlights instead the issues that do need to be the subject of serious debate, but are rarely discussed: (1) the continued separation of 'technical' issues of safety and efficacy from 'moral' issues associated with the technology; (2) lack of attention to the infrastructure and practices of the for-profit fertility industry through which embryo editing will potentially be offered to the public; and (3) an over-simplistic formulation of 'consensus'. In the following sections, we will discuss each of these as part of the history of biotechnology. To clarify our analysis, we will use Mary Douglas' concept of 'matter out of place' as a lens through which to understand, and rehabilitate the concerns raised by various publics about novel biotechnologies, from Dolly the cloned sheep 
to 'designer babies'. Adapting this stance for future engagement activities about GGE, we argue, provides a way of avoiding a narrow separation of safety risks from broader societal concerns, and reintegrates discussion of science policy and the role of the private sector as a legitimate part of the public conversation.

\section{A brief history of biotechnology}

First generation' genetic modification is an important antecedent of contemporary genome editing technologies like CRISPR (Martin et al., 2019). Recombinant DNA (rDNA), in which sequences of DNA are cut out of, or added to the 'host' DNA in the living cells of an organism, was invented in the early 1970s by researchers working at Stanford University and the University of California, San Francisco. Although excited by the possibilities this new technique opened up, there was also concern about potential undesirable effects, especially since many of the first organisms to be genetically modified were bacteria. As an initial response, a moratorium on further genetic engineering was voluntarily imposed by the (relatively small number of) scientists working with rDNA. In 1975, at the now-historic Asilomar meeting, this temporary ban was replaced with a set of selfdeveloped guidelines under which scientists felt the field could safely proceed (Baltimore et al., 2015) and which has to some extent guided all experimentation involving manipulation of DNA since.

The possibility of using rDNA technology to modify human genetic material has been part of the conversation, though not practice, from the beginning. Following an unapproved, and unsuccessful, attempt in 1980 to treat sickle cell disease using rDNA (see Beutler, 2001), the US President's Commission for the Study of Ethical Problems in Medicine, and Biomedical and Behavioral Research issued a report, 'Splicing Life' (1982), which codified and popularised two key distinctions that continue to shape discussions of human genetic modification to this day: treatment of disease versus enhancing normal human characteristics, and making non-inheritable changes to the genome of individual patients versus making changes to embryos, sperm or eggs that can be passed on to future offspring-often described pejoratively in popular accounts as creating 'designer babies' (Nerlich, 2017).

While these events were unfolding, research was being carried out in a number of seemingly unrelated areas that would nonetheless have an important role in eventually making GGE a practical reality. In 1977, Frederick Sanger and colleagues developed the technique known as 'Sanger sequencing', allowing scientists to better read the sequence of letters (or 'base pairs) in DNA. The following year, the birth of Louise Brown in the UK proved that conception could occur outside the human body, through the technique of in vitro fertilisation (IVF) developed by Robert Edwards and Patrick Steptoe. Together, these events made the human embryo available for direct experimentation and provided the beginnings of a toolkit for manipulating its DNA. ${ }^{3}$

By the early 90s, genetic sequencing had advanced sufficiently to make it feasible, if hugely ambitious, to attempt to sequence a complete set of human DNA, forming the basis of the international Human Genome Project (HGP). The 90s also saw the birth of Dolly the Sheep, the first large mammal to be successfully cloned; commercialisation of the first crops genetically modified using rDNA technology; derivation of stem cells from human embryos; and the 'ear mouse', produced by engineering a structure resembling a human ear on the back of a laboratory mouse. More recently we have seen the production of 'admixed' embryos containing both human and animal material and mitochondrial transfer (i.e., combining cytoplasm from one egg with the nucleus of another) to produce so-called 'three-parent babies'. These technologies have been highly controversial in some countries (Baylis, 2013; Cook-Deegan, 1994; Knoppers et al., 2017; Marris, 2001; Mulkay, 1997) but allowed in others. Pre-implantation genetic diagnosis (PGD), for example, is particularly contentious in Germany because of its association with Nazi-era eugenics, whereas the UK allows admixed embryos, PGD and mitochondrial transfer under specific circumstances, overseen by the HFEA.

All of these advances have also involved contestation by various 'lay' publics, i.e., people and groups who are neither professionally trained in the life sciences nor officially charged with oversight of biotechnologies, such as the staff of regulatory agencies or members of ethics panels. Even when unsuccessful, such opposition is, we hold, still significant if calls for socially responsive steering of science and technology are to be taken seriously. By this, however, we do not mean to suggest there is some homogeneous 'general public' that has a single voice and set of concerns. Opposition typically comes from a variety of publics, brought into being around different issues through a variety of methods, and not necessarily in the same place or at the same time. These include protests and boycotts, official engagement events, attitude surveys and televised debates, all of which are seen as representing a 'public voice', yet this is by no means a unified voice. In the following sections, we discuss these frictions as part of the business of science, detailing how previous encounters affect the context of deployment of CRISPR, the separation of technical from ethical issues, and place an emphasis on high-level consensus engagements that are not actually fit for the purposes of real governance.

\section{The business of science}

The constant stream of new biotechnologies that began in the latter half of the twentieth century is not co-incidental. The era of biotechnology aligns with a profound shift in the political and economic landscape of science. National governments, the major funders of academic science, increasingly look for a return on their investment of public money in research in the form of new products and services that can foster national economic growth (Hessels et al., 2009). Scientific knowledge is privatised through intellectual property rights, and companies are commonly 'spunout' of university departments to exploit knowledge and technologies developed by their academic scientists. For example, rDNA was patented in 1974 by the scientists who discovered it and subsequently licenced by Stanford University to various commercial developers for a fee, plus a share of royalties from subsequent products (Feeney et al., 2018). The Bayh-Dole Act of 1980 formalised this approach by incentivising US scientists and universities to patent and commercialise the products of government-funded research. A US Supreme Court decision of the same year, Diamond vs. Chakrabarty, allowed intellectual property rights to be granted on a living organism. Other nations, with greater or lesser alacrity, have adopted and adapted this US approach to science as a source of economic growth and national competitive advantage (Rajan, 2006). GM plants and animals, stem cells, genetic tests and processes for creating "life itself are all now commercial products, patented and traded by start-up firms and multinational companies in a highly lucrative 'bioeconomy'. Nowhere has this shift from publicly funded experiment to profit-driven sector been more evident than the fertility industry.

Within a few years of Louise Brown's birth, in vitro conception had evolved from an experimental procedure in which few scientists were interested, into a rapidly burgeoning industry dependent upon aggressive marketing and constant innovation, the brunt of which is borne by women, upon whose bodies the 
entire process depends (Rowland, 1992). As IVF is a platform technology, making the human embryo scientifically accessible quickly gave rise to associated services such as surrogacy, sex selection and PGD, which have continued to be controversial, expensive and unevenly governed on a global basis.

In both the fertility and the larger biotechnology industry, national policy, which sees science as a source of international competitiveness, prestige and economic growth, has helped to foster rapid application of each new discovery. Australia, for example, funded IVF research with the explicit goal of putting the country on the international map, and by 1984, the team at Monash University in Melbourne had overtaken the UK as the world-leader with a series of other firsts, including twins, triplets, babies born from donor eggs and from frozen embryos (Kannegiesser, 1988). Thus, national aspirations also act as an engine for pushing biotechnologies out of the laboratory and into the public sphere, where they often become controversial because of their seemingly sudden impact on everyday life, from what we eat to how we reproduce.

Rapid innovation, particularly through embryo experimentation, also prompted regulatory responses from a number of nation states throughout the 1980s. The Warnock Commission (UK) proposed that research on embryos could be permissible up to 14 days, but that no embryo that had been altered could be returned to the womb with the intention of creating a child (Warnock, 1985). This regulatory model has had such a widespread influence that "almost every country in which embryo research is specifically permitted by regulation, soft or hard, employs a version of the 14-day rule" (Chan, 2018, p. 228).

The successful early reframing of IVF from 'experimental' to infertility 'treatment', even for conditions where infertility is not the issue (such as artificial insemination for single women, PGD for embryo selection, or surrogacy for social reasons) has relied upon the argument which supports most biomedical innovation: that it will alleviate human suffering. Moreover, the field has successfully embedded the logics of clinical experimentation, in which patients have a right to unproven treatments if they and their doctor think it may confer benefits worth the risks (Baylis, 2013).

While public funding of basic research was essential to development of the field, private clinics have also existed almost from the start, including Bourn Hall in the UK, founded by Edwards and Steptoe in 1980. With most public healthcare systems now providing only limited access to IVF and related services, a global market for private assisted reproductive services has emerged, both in western countries (Spar, 2006; Van Hoof and Pennings, 2011) and increasingly in Asia (Whittaker, 2011). As a result, what is now more broadly called 'fertility treatment' has grown into a highly lucrative globalised industry where those with the money to travel can purchase services which are unavailable or even illegal at home, and innovation takes place in an atmosphere of secrecy and fierce competition. The recent birth of the Chinese twins shows that, as with virtually all innovation in assisted reproduction, experimentation can go unnoticed, even be deliberately hidden, until a 'success' can be announced.

Separating the technical from the moral. Unease, disquiet and even disgust at the rapid appearance of biotechnology has been memorably characterised as the 'yuck factor' by philosopher Leon Kass (1998), who identifies it as part of a 'wisdom of repugnance' stemming from a natural human recognition of things that are ethically dubious. However, other philosophers have viewed this as an uninformed and thus discountable emotional reaction, rejecting the idea of the 'unnatural' as having any moral validity (e.g., Kaebnick, 2012). In keeping with this line of thought, opposition to technology is often characterised by scientists, policymakers and technology companies as irrational or opposed to science and progress, a stance closely associated with what has become known as the 'deficit model' of public understanding of science (Davies, 2006; Marris, 2001; Simis et al., 2016; Wynne, 2001). Put simply, the deficit model posits that public unease about novel science and technology is a result of poor scientific literacy; therefore, educating the public about the science behind new technologies will foster acceptance.

Governance of science and technology also tends to leave 'societal' concerns outside the scope of formal regulatory oversight (c.f. Levidow and Carr, 1997). For example, the US Patent and Trademark Office has argued it cannot incorporate consideration of the moral and social aspects of granting intellectual property rights on living materials into its remit because this would introduce an unacceptable element of uncertainty into assessment procedures which must remain objective (Parthasarathy, 2017). In other instances, societal concerns may be acknowledged by a regulatory agency but still considered separately from its technical remit, through public fora and engagement exercises such as those deployed by the HFEA during the debates over allowing the creation of admixed embryos to alleviate the shortage of human ova for stem cell research (Dyer, 2008). In the European debates over regulation of GM foods, most engagement occurred after vociferous public resistance to an approved product, in the hope of creating enough acceptability (often through attempts to de-legitimise nontechnical concerns) to allow the original agenda to proceed. Particularly because of the continued European rejection of GM, 'upstream' (i.e., research-stage) engagement is now often regarded as a tool to prevent these kinds of market failure (Marris, 2015).

The equation of non-technical concerns with ethics (Levidow and Carr, 1997) also means that public debates are often framed in terms of whether it is morally permissible to undertake a particular scientific act, such as destroying an embryo or changing the genetic make-up of a living organism. This is perhaps most vividly illustrated in the creation of a separate line of scholarship about the ethical, legal and social issues (ELSI) arising from the HGP (Myskja et al., 2014). Combined with the deficit model, this means exercises are often framed so that technical assertions cannot be challenged, reinforcing the idea that objections reflect an ill-informed response. Wider discussions about the commercialisation of science, economic aspirations of national governments, and the role of the private sector in envisaging what future agriculture, medicine and reproductive health services should look like, are said to be outside the remit of regulation. Moreover, approaching each novel biotechnology as a discrete entity precludes adequate consideration of the way discoveries build on and integrate with one another, so that-as with designer babies until this year-controversial possibilities for application can then be dismissed as 'too far in the future to be worthy of debate'.

Oversimplifying consensus. Well before He Jiankui's activities, genome editing was the subject of a plethora of high-level meetings, workshops, reports and position statements by groups ranging from national funding organisations to supranational political entities and learned societies (The Hinxton Group, 2015; Nuffield Council on Bioethics, 2016; National Academy Of Sciences; National Academy Of Medicine, 2017; Nicol et al., 2017; Garden and Winickoff, 2018). While these differ in their focus, e.g., whether they deal exclusively with human applications or consider genome editing in a variety of organisms, virtually all reports and statements call for robust public engagement in order to determine the trajectory of research and eventual applications 
of the technique. However, it remains unclear how any resulting public consensus should be measured, let alone how it is expected to be achieved.

Whether by design or serendipity, calls for public consensus allow science to continue pushing at the moral boundaries already in place, testing for strengths and weaknesses to see where pressure may be applied. In part, this is because public engagement has generally been the task of ELSI scholars, while the natural scientists and clinicians get on with the work. This is clearly demonstrated in both the discussions and the division of expertise in the panels at the Human Gene Summits of 2015 and 2018. However, there is virtually no likelihood that, should consensus fail to appear, further research and application of CRISPR to the human germline will not proceed. ${ }^{4}$ Just as assisted reproduction has expanded into a cross-border industry where would-be parents frequently travel in order to obtain reproductive services that are illegal in their own country, IVF doctors pursuing controversial innovation also move or open satellite clinics in jurisdictions that are less restrictive (Rosemann et al., 2019). ${ }^{5}$ Because courts tend to rule that preservation of family bonds, including non-prosecution of parents who break the law, is in the best interest of the child (Van Hoof and Pennings, 2011), this has meant almost any prohibited procedure is available somewhere. Similar dynamics have also been seen with the spread of stem cell clinics (Petersen et al., 2017) which rests on the patient's perceived 'right to try' even risky, unproven procedures. Ultimately, there is a real danger that the stand-in for 'public consensus' will simply be that some people are willing to go anywhere and pay any price to have what they want.

To be meaningful and useful, public debate must therefore move beyond the goal of consensus, which implicitly suggests that there is a single voice, or agreement on how to move forward, that can and must be found. Taking public concerns seriously (that is, as rational and legitimate) also means recognising that there are multiple publics and indeed multiple rationalities, and that debate over any particular biotechnology will almost certainly play out differently in different contexts. If consensus means that everyone, or at least the vast majority of people, must agree that a technology is acceptable, then true consensus is very rarely if ever achieved at a societal level-never mind on a global scale. If debates about using CRISPR to create genetically modify human embryos are to avoid simply repeating the same arguments which have existed since the 1970s, then new approaches are needed that go beyond the polarised notion of rational science versus irrational ignorance, and technical versus moral concerns. This means opening up debates involving both lay people and scientists to include discussion of the context-including the economic and regulatory context(s) - in which GGE will be deployed. Achieving this is not simply a matter of doing 'better' engagement-at least not without a discussion of what 'better' might mean. In the next section, we present an alternative approach to understanding public concerns with biotechnologies, with a view to informing our recommendations on the future of germline genome editing debates.

\section{Biotechnology, hybridity and matter out of place}

In her now-classic anthropological study, Purity and Danger, Mary Douglas (1966 [2001]) set out to explore why some objects, behaviours, or situations are considered 'clean' or 'pure' while others are regarded as 'dirty', 'polluting' or 'contaminating'. One of her key findings was that there is rarely any universal substance or action that is considered 'dirty', but what almost all societies think of as 'dirt' is something that is not where it is supposed to be, i.e., it is 'matter out of place'. Boundaries and categories, whether formal and official or tacit and unspoken, produce order, the sense of how things are supposed to be, but what is applicable in one context may cease to make sense, may even be offensive, when transposed to another. This can be illustrated with a simple example: soil found in a flowerbed is not dirt. That is where we expect it to be. However, the same soil on the kitchen floor is considered dirt and the normal response is to clean it up. It is not that 'soil' is never or always 'dirt'; rather it depends on the context and on our prior expectations of where soil ought and ought not to be.

Although Douglas' work primarily explored beliefs and practices of ritual pollution in tribal societies, the underlying anthropological understanding is equally applicable to modern cultures. Thus, it helps us see how investigation of the plasticity (or malleability) of life, which has proved so productive and useful in the laboratory, also challenges categories and distinctions that have meaning and are important in everyday life outside the laboratory.

Categories and distinctions-for example between soil and dirt, animal and human, or between the embryo in the body and the embryo in the dish, define what we think of as 'normal', 'proper', and 'expected', to the extent that we rarely recognise that they result from particular judgements and assumptions until they are in some way challenged. Things, situations or actions that cross boundaries or appear to simultaneously belong to distinct oppositional categories (hybrids) become viewed as 'dirty', 'dangerous', 'unnatural', 'monstrous' or 'impure'. Each of these accusations evokes a sense of some sort of order being transgressed, whether that order is imposed by nature, divine fiat or aesthetic and moral sensibilities. Cell culture, for example, problematizes the boundary between what is alive and what is dead or inert. Consider Henrietta Lacks, who died many years ago but whose cancer cells, in the form of the immortalised HeLa cell line, are still alive and growing in many laboratories round the world (Skloot, 2011). Reproductive cloning, mitochondrial and gamete 'donation' and surrogacy all challenge conventional ideas of family relations in terms of who counts as a parent or a sibling. Reproductive cloning also blurs distinctions as it makes a new person whose genome replicates someone already living, or perhaps already dead (the difference in age typically distinguishing cloning from ordinary twins). Genetic modification of human embryos using genome editing produces a similarly troubling hybrid: the CRISPR babies are both 'natural' given persons and engineered 'objects' of laboratory science, both who and not who they were originally 'intended' to be. Thus, hybrid biotechnologies appear to pose a threat to the shared meanings, values and rules of conduct that make communal social living and organisation possible. Part of what constitutes the yuck or fear response to these technologies, we argue, is a shared (though often tacit) sense that matter has somehow been shifted out of its 'correct' or natural place.

The hybrid-generating power of the life sciences is rarely experienced by the scientists themselves as unnatural or disturbing because the techniques they use have long since been normalised within the field. This perspective is the result of years of training to seek knowledge in a particular manner, encompassing both ontology (what kinds of objects genes, cells, embryos, etc. are), and epistemology (how they should best be studied and how experiments should be designed). The array of practical tools and techniques for manipulating cells, genes, proteins and other elements of living systems are learnt, along with the cognitive stance that makes sense of them, through the process of training from undergraduate to post-graduate to postdoctoral to senior scientist. This combination of a particular way of looking at the world and a set of techniques for producing knowledge based on that perspective is what Karin Knorr-Cetina (1999) described as the peculiar 'epistemic culture' of a discipline. 
As Douglas (1966, p. 45) notes, "our pollution behaviour is the reaction which condemns any object or idea likely to confuse or contradict cherished classification". It is, therefore, culturally specific, but contemporary societies are much more heterogeneous and fragmented than tribal groups or the epistemic cultures of scientific disciplines. Accordingly, there is often a range of different responses and attitudes to novel biotechnologies within any given population, some of which are voiced more loudly than others. Different forms of pollution may produce a similar result, despite different cultural or epistemic rationales, or vice versa. For example, while religious groups may object to embryo experimentation because it pollutes the embryo, feminists might object to the pollution of women's bodies, because the arduous process of egg extraction means women are being asked to bear unnecessary medical risks purely to advance science and scientists' careers (see e.g., Waldby, 2008; Baylis, 2013). Thus, while both groups might oppose creating embryos for stem cell research, it would be for very different reasons and require different 'rituals of purification'.

The designation of a thing, event, deed, or person as 'dirty' and 'out of place' is rarely an unalterable verdict as "most pollutions have a very simple remedy for undoing their effects. There are rites of reversing, untying, burying, washing, erasing, fumigating, and so on" (Douglas, 1966, p. 168). Just as 'matter out of place' can be a cultural and symbolic judgement rather than a literal material one, so too can acts of purification operate as symbolic restitution, rebalancing the social order rather than fixing a physical problem. In contemporary societies, a public engagement exercise that is perceived as meaningful might act as a suitable 'rite of purification'. It is publicly enacted, so its message would be transmitted to the wider society, and its procedures must symbolise some form of democratic accountability and legitimacy sufficient to dispel lingering doubts about the danger of a 'messy' new hybrid technology. Similarly, in the widespread condemnation of He Jiankui's GGE experiment by scientific authorities and bioethicists we can see an attempt at purifying human GGE research by designating Jiankui as a 'rogue' scientist, symbolically expelling him from the global community working on the topic, and distancing his 'dirty' work from the 'pure' realm of legitimate science (e.g., Regalado, 2018c; Harper, 2018; Belluck, 2019).

At the same time, the infrastructure and practices of the biotechnology industry have become increasingly universal as more countries compete to enter the global market. Intellectual property regimes now apply to living organisms and their components (such as genes, cells and proteins), with material from plants, animals, and even people with particular characteristics extracted and invested in as sources of 'biovalue', while biotech start-ups commercialise novel discoveries through speculative investment and academic scientists increasingly act as entrepreneurs (Rajan, 2006; Waldby and Mitchell, 2006). The sense of matter out of place can be very strong here as most cultures have not historically considered these kinds of biological material as a resource which can be patented and sold, particularly in a way that allows others to profit from our bodies in ways we cannot, as in the case of Henrietta Lacks' cancerous cells.

Thus the infrastructure of the biotechnology and fertility industries pushes matter across normative boundaries between private and public property, between publicly funded academic science and for-profit industry, between the body and the patent office, and between pure science-investigating what something is or how it works-and forms of applied science which are meant to see what things can be made to do. As Smits (2006, also following Douglas) has observed, hybrid entities are often seen as 'monstrous' in that they simultaneously and inextricably arouse both fear and fascination (see also de Saille and Martin, 2018). This makes highly visible biotechnologies like Dolly the Sheep or the 'designer baby' a focus for airing broader concerns about purity and impurity in the scientific endeavour that may otherwise fail to find an outlet. The outpouring of scientific condemnation for He's GGE procedure, although intended to 'purify' the field of genome editing, also served to reopen discussion about the moral appropriateness of the incentive structures in modern science, including the prestige associated with being the first to make each advance and the pressure to commercialise research. Ultimately, each new symbol of biotechnology evokes culturally specific reactions and simultaneously becomes a new instance to refight old battles.

Applying the 'matter out of place' approach to GGE means that, rather than accepting the charge that expressions of disgust, monstrosity or unnaturalness are evidence of irrational fear and ignorance in public debates, we should actively look for what is being designated as 'dirt' by different speakers and different constituencies, and what kinds of purification rituals are being called into play. This in turn reframes GGE not as an abstract ethical question about the moral boundary of a particularly technology, but as a systemic question about the wider context of existing social structures, and the kinds of checks, incentives and rituals which will be needed to keep it-and indeed whether it is even possible to keep it-'clean'.

At the beginning of this paper, we noted that it was not just a matter of what He did, but when. He's experiment invited condemnation on a number of what grounds: that there are better treatments to prevent HIV transmission, that his consenting procedure was highly unethical, and that his own tests showed the edits were de novo mutations that would be ineffective to prevent HIV in one, perhaps both embryos, so there was no scientifically supportable reason to continue. These arguments would be enough to designate the experiment 'dirty', even if GGE was legal and accepted. But perhaps more important, He contravened what might be the most important cleanliness taboo because it is the only one approaching unanimous agreement by all parties in the field: that GGE is not safe enough to be used yet. This could be seen in arguments that the experiments were premature, and could damage the legitimacy of the field. However, He could also be seen as polluting the sacred ritual of public consensus seeking by the timing of the announcement, which effectively hijacked the carefully curated agenda of the second Human Gene Summit, turning it instead into a media circus which-as feared from the start-forced the entire field into a defensive position from which it is still trying to emerge.

\section{CRISPR in context-towards a socially responsive debate on embryo editing?}

CRISPR excites scientists and clinicians because it opens new possibilities for research and innovation, but mindful of past controversies, they also worry that a public backlash against germline genome editing could threaten both somatic (i.e., nonreproducing) genome editing and embryo research in general. This fear of a public backlash shapes the field in particular ways; even those who champion GGE for human enhancement are enjoined to limit the scope of their research to what is within their so-called social licence to operate. ${ }^{6}$ Calls not to operate before there is public consensus are a key part of this protective strategy. Thus, condemnation of He Jiankui was a necessary part of 'purifying' a polluted field.

Let us be clear that we are not arguing against dialogue and engagement. Our concern is that, if dialogue is to be meaningful, it must have a different purpose, as 'consensus' already appears to exist insofar as survey instruments show that public opinion is broadly similar across time and place. We offer instead the idea of 'matter out of place' as a way of working through the three main 
lacunae identified in discussions about novel biotechnologies: (1) persistence of a deficit model framing that presents lay opposition as resulting from irrationality, fear and/or ignorance; (2) separation into technical criteria to be assessed by scientific experts, and moral concerns to be addressed by ELSI scholars and public engagement exercises and (3) discussion of each new technology as a separate 'ethical' issue with little or no consideration of the context within which science in general and assisted reproduction in particular is organised, funded and commercialised. These elements are best considered as acting cumulatively, with each reinforcing the other.

In the preceding sections, we have tried to situate CRISPR in its context as a new biotechnology, but one which does not represent a significant departure from the trajectory of the field. Rather, the birth of two genetically edited children is the long-expected, yet still seemingly premature, culmination of experiments aimed at manipulating DNA which began in the 1970s. The history of the life sciences (especially molecular biology) is one of progressively investigating the malleability of life, so that for its practitioners moving, mixing and mutating its elements has become a perfectly normal, acceptable way of producing knowledge. However, these manipulations also transgress boundaries that are meaningful and significant in everyday life: alive/dead, old/young, human/animal/ plant, etc. This may not matter when scientific research remains 'behind the scenes' in the laboratory, unless it involves things that already have a special social status, such as human embryos. However, the contemporary emphasis on the life sciences as a source of economic growth and national prestige, combined with a 'translational imperative' which regards the overriding purpose of academic research as the generation of new products and services, serves to accelerate both the volume of hybrid entities being produced and the speed at which they move 'front stage' into the public gaze.

As with the muddy road from IVF to human cloning to mitochondrial donation, sustaining boundaries between therapeutic and reproductive applications may be more difficult than might be hoped. While the boundary between somatic and germline editing is reinforced through the Human Gene Summits and other such discussions, the context in which those boundaries have been constructed (and will likely be dismantled) is not discussed. Whether one approves of GGE or not, it must be noted that He Jiankui already considered it as a 'therapeutic assisted reproductive technology' (He et al., 2018), and there are already IVF clinics eager to learn his technique (Begley, 2019). In such a highly competitive industry, history has already shown us that once one clinic innovates, the sector will shortly follow.

There is, therefore, a real danger that the lack of public protest over He's announcement will be taken for public consensus to proceed. To some extent, this lack may have been an artefact of a particular political moment in which other things-climate change, far-right extremism and an unstable White House-were dominating both news cycles and the public mind, exhausting the capacity to worry about two children born through some obscure technology in China. However, it can also be seen as a reflection of previous battles over biotechnological innovation, a kind of weariness stemming from the public's sense that we have been here many times before and there is little to be said that is new. Rather than a social license to operate, this indicates a not entirely unfounded pessimism that whatever objections might be raised, the science will continue, as has been the case with embryonic stem cells or GMOs.

We see this weariness as the inevitable result of a deficit approach which frames rational science as struggling against an ignorant public. One reason this practice continues is because it privileges scientific expertise and the scientific worldview as the starting point for being able to have any valid say in these discussions (Jasanoff, 2011). This allows those with technical expertise to remain on familiar, quantifiable ground in which science is a value-free account based on reason and evidence alone, and avoid questions which are non-quantifiable and outside their narrow expertise. This dualistic stance actively favours the silo approach, where scientific research is permitted to continue unimpeded with the justification of amassing the data needed to satisfy objective regulatory criteria for safety and efficacy, while non-technical societal concerns are dealt with separately as subjective matters that cannot be adjudicated by evidence. Within this context, potential harms can only be considered as issues of safety and efficacy, while contextual factors such as facilitating markets, distribution of benefits and risks, and complexities of global governance are bracketed out. Thus, the debate narrows down to the moral permissibility of a scientific procedure in the abstract, so that 'to alleviate human suffering' becomes a moral trump card, an unassailable justification for proceeding, regardless of whether human suffering is being created at the same time.

We find this approach unsatisfactory for a number of reasons. First, the deficit model privileges expert definitions of the problem and of what is at stake over those of lay publics who nevertheless have to live with the consequences. The separation of 'ethical' and 'technical' aspects precludes meaningful discussion of the social contexts in which technologies are developed and made available. Consequently, the interests of states and technology developers are prioritised over those of the people and communities affected by the implementation of new technologies, in ways that lack democratic legitimacy and may inhibit socially responsible innovation. Further, debates on effective governance solutions tend to remain the preserve of technical experts who may not have sufficient information to see the bigger picture.

We initially introduced 'matter out of place' as a way of seeing lay concerns about new technologies as rational, understandable, socially responsive reactions to the hybrid nature of many biotechnologies. However, like the technologies in question, publics also appear to simultaneously elicit both fear and fascination for the scientists who must ultimately justify their research in order to ensure their social license to operate. While publics worry about risks both expected and unforeseen, scientists also worry that engagement exercises can risk uncovering serious negative responses, or that 'unruly' publics may turn confrontational and begin to actively resist, as in the case of GMOs. Thus, although the agency of publics in technical decision-making may be limited and reactive, it is not non-existent. We propose further extending the idea of 'matter out of place' to bring this context-especially the context(s) under which science is produced, new technologies are made available, and people make choices based on their own needs and desires-back into public debates about GGE. This shows us that publics themselves are often treated as 'matter out of place' in scientific engagement exercises, subjected to a variety of rituals to ensure they are 'clean', such as pre-screening focus groups to weed out those with existing or unfavourable opinions, limiting responses in written consultations to technical issues only, or requiring that audience questions at expert panels be submitted to a moderator, who then chooses which will be answered. This erodes both democratic legitimacy and trust (Marris, 2015; Wynne, 2001).

Second, we do not believe it is appropriate for public approval to be measured by take-up through the market. This cannot stand in for social licence to operate because the latter requires a collective, rather than individualist, view which must consider what will happen if the technology is taken up in aggregate. Many technologies cause little harm when only a few use them, but have substantially different effects once they become ubiquitous. If, for example, it becomes a moral obligation to edit all of our embryos 
to make the "best possible babies", as Savulescu (2007) and others have suggested, that would also require all women who want children to undergo IVF, a context which is not mentioned.

Third, as long as the goal of achieving public consensus remains a priority for many policy makers and scientific authorities (Rosemann et al., 2019), our (modest) recommendation is that these must engage robustly with what is meant by 'consensus' and how we will know that it has been achieved. It also means recognising generic, recurring concerns about the nature of the biotechnology industry and understanding these as not wholly separable from concerns specific to a particular technology. Rather than consensus about acceptable and unacceptable uses of technology in the abstract, we suggest the aim of engagement should be to try to find new and alternative ways of interrogating the context of technological deployment as much as the technology itself. Adopting a 'matter out of place' approach directs attention to how GGE's specific inseparable but incommensurate categories might be pointing to a genuine threat to values, meanings, ways of life, and hopes for the future, as well as traditional scientific understandings of harm, and consider opposition as rituals of purification and/or containment which have a rational purpose. This includes debates on the acceptability of commercial delivery of GGE through private clinics, the possibility of reproductive tourism, and the way contemporary science is incentivised. This, as we have argued, is not aimed at producing consensus, but at making debates about GGE more sensitive to the variety of perspectives and concerns (as well as hopes) it calls forth. Ultimately, 'matter out of context' is not a panacea for all issues of responsible research and innovation in GGE-a wicked problem with no easy solutions if ever there was one-but we believe it can provide a more useful way of framing an equitable public debate.

\section{Data availability}

No datasets were generated or analysed.

Received: 19 June 2019; Accepted: 5 September 2019;

Published online: 24 September 2019

\section{Notes}

1 Elsevier (2017) Gene Editing Research. https://www.elsevier.com/research-intelligence/ campaigns/crispr.

2 Including Feng Zhang of the Broad Institute, who holds the patent He licensed for his work (Regalado, 2018a).

3 Robert Edwards himself was acutely aware of this potential (see Edwards and Glass 1976).

4 Indeed, as we were writing this article, a Russian scientist claimed he would replicate He's CCR5 experiment because he was 'crazy enough' to try (Cyranoski, 2019). Then, after widespread condemnation, he decided to edit for deafness instead (Le Page, 2019).

5 John Zhang, the IVF doctor trying to commercialise nuclear spindle transfer (a form of mitochondrial donation) for older women, is explicit about this: the embryos are made in his New York lab but are implanted in his satellite clinic in Mexico because this is illegal in the US. Designer babies are his declared next step (Mullin, 2017), having discussed the 'potential' of setting up a clinic in China with He in the summer of 2018 (Cohen, 2019).

6 However, this does not seem to stop clinics from promising 'better babies' by preadvertising PGD-related services which do not yet exist, such as selecting embryos for intelligence (Devlin, 2019).

\section{References}

Araki M, Ishii T (2014) International regulatory landscape and integration of corrective genome editing into in vitro fertilization. Reprod Biol Endocrinol 12(1):108-120

Baltimore D, Berg P, Botchan M, Carroll D, Charo RA, Church G et al. (2015) A prudent path forward for genomic engineering and germline gene modification. Science 348(6230):36
Baylis F (2013) The ethics of creating children with three genetic parents. Reprod BioMedicine Online 26(6):531-534

Begley S (2019) Fertility clinics around the world asked 'CRISPR babies' scientist for how-to help. STAT. https://www.statnews.com/2019/05/28/fertilityclinics-asked-crispr-babies-scientist-for-how-to-help/. Accessed 28 May 2019

Belluck P (2019) How to stop rogue gene-editing of human embryos? The New York Times https://www.nytimes.com/2019/01/23/health/gene-editingbabies-crispr.html. Accessed 15 Aug 2019

Beutler E (2001) The cline affair. Mol Ther 4(5):396-397

Chan S (2018) How and why to replace the 14-day rule. Curent Stem Cell Rep $4: 228-234$

Cohen J (2018) 'I feel an obligation to be balanced.' Noted biologist comes to defense of gene editing babies. Science https://doi.org/10.1126/science. aaw2120.

Cohen, J (2019) The untold story of the 'circle of trust' behind the world's first gene-edited babies. Science https://doi.org/10.1126/science.aay9400.

Cook-Deegan RM (1994) The gene wars: science, politics, and the human genome. WW Norton \& Company, New York

Cyranoski D (2019) Russian biologist plans more CRISPR-edited babies. Nature 570:145-146

Davies G (2006) The scared and the profane: biotechnology, rationality and public debate. Environ Plan A 38(3):423-443

de Saille S, Martin P (2018) Monstrous regiment versus Monsters Inc: Competing imaginaries of science and social order in responsible (research and) innovation. In: Nerlich B, Hartley S, Raman S, Smith A (eds) Science and the politics of openness: Here be monsters. Manchester University Press, Manchester, p 148-166

Devlin H (2019) IVF couples could be able to choose the 'smartest' embryo'. The Guardian. https://www.theguardian.com/society/2019/may/24/ivf-couples-couldbe-able-to-choose-the-smartest-embryo. Accessed 24 May 2019

Doudna JA, Charpentier E (2014) The new frontier of genome engineering with CRISPR-Cas9. Science 346(6213):1258096

Douglas M (1966) Purity and danger. Routledge, London

Dyer C (2008) Bill allowing creation of "admixed" embryos for research passes first hurdle. Br Med J 336(7653):1089-1089

Edwards R, Glass B (1976) Fertilization of human eggs in vitro: morals, ethics and the law. Q Rev Biol 51:367-391

Feeney O, Cockbain J, Morrison M, Diependaele L, Van Assche K, Sterckx S (2018) Patenting foundational technologies: Lessons from CRISPR and other core biotechnologies. Am J Bioeth 18(12):36-48

Garden H, Winickoff D (2018) Gene editing for advanced therapies: Governance, policy and society. OECD Science, Technology and Industry Working Papers, 2018/12. OECD Publishing, Paris

Harper J (2018) World's first gene-edited babies? Premature, dangerous and irresponsible. The Conversation. https://theconversation.com/worlds-first-geneedited-babies-premature-dangerous-and-irresponsible-107642. Accessed 15 Aug 2019

Hessels LK, Van Lente H, Smits R (2009) In search of relevance: the changing contract between science and society. Sci Public Policy 36(5):387-401

The Hinxton Group (2015) Concensus statement on genome editing technologies and human germline. http://www.hinxtongroup.org/Hinxton2015_Statement. pdf. Accessed 4 Aug 2019

He J, Ferrell R, Yuanlin C, Jinzhou Q, Yangran C (2018) Draft ethical principles for therapeutic assisted reproductive technologies. CRISPR J [retracted]. https:// doi.org/10.1089/crispr.2018.0051.retract.

Hendriks S, Giesbertz NAA, Bredenoord AL, Repping S (2018) Reasons for being in favour of or against genome miodification: A survey of the Dutch general public. Human Reproduct Open 2018(3). https://doi.org/10.1093/hropen/ hoy008.

Jasanoff S (2011) Constitutional moments in governing science and technology. Sci Eng Ethics 17(4):621-638

Kannegiesser H (1988) Conception in the test tube: the IVF story, How Australia Leads the World. Macmillan, South Melbourne

Kass LR (1998) The wisdom of repugnance: why we should ban the cloning of humans. Valpso Univ Law Rev 32(2):679-705

Kaebnick GE (2012) Its against nature. Hastings Cent Rep 39(1):24-26

Knoppers BM, Leader A, Hume S, Shoubridge EA, Isasi R, Noohi F et al. (2017) Mitochondrial replacement therapy: the road to the clinic in Canada. J Obstet Gynaecol Can 39(10):916-918

Knorr-Cetina K (1999) Epistemic cultures: how the sciences make knowledge. Harvard University Press, Cambridge

Lander E, Baylis F, Zhang F, Charpentier E, Berg P (2019) Adopt a moratorium on heritable genome editing. Nature 567:165-168

Lawton G (2018) Hope for the future. New Scientist 239(3196):6-7

Le Page M (2019) Next CRISPR babies planned. New Scientist 243(3238):8

Levidow L, Carr S (1997) How biotechnology regulation sets a risk/ethics boundary. Agriculture Hum Values 14(1):29-43 
Marris C (2001) Public views on GMOs: deconstructing the myths: Stakeholders in the GMO debate often describe public opinion as irrational. But do they really understand the public? EMBO Rep 2(7):545-548

Marris C (2015) The construction of imaginaries of the public as a threat to synthetic biology. Sci Cult 24(1):83-98

Martin P, Morrison M, Turkmendag I, Nerlich B, McMahon A, de Saille S, Bartlett A (2019) Genome editing: the dynamics of continuity, convergence and change in the engineering of life. New Genet Soc

Michie M, Allyse M (2019) Gene modification therapies: views of parents of people with Down syndrome. Genet Med 21:487-492

Mole B (2016, November 20) Florida officials move forward with GM mosquitos, despite bitter foes. Ars Technica. https://arstechnica.com/science/2016/11/ swatting-away-angry-locals-florida-officials-approve-gm-mosquito-trial/. Accessed 26 July 2019

Mulkay MJ (1997) The embryo research debate: science and the politics of reproduction. Cambridge University Press, Cambridge

Mullin E (2017) The fertility doctor trying to commercialize three-parent babies. MIT Technology Review https://www.technologyreview.com/s/608033/the-fertilitydoctor-trying-to-commercialize-three-parent-babies/. Accessed 13 June 2019

Myskja BK, Nydal R, Myhr AI (2014) We have never been ELSI researchers-there is no need for a post-ELSI shift. Life Sci Soc Policy 10:9

National Academy Of Sciences; National Academy Of Medicine (2017) Human Genome Editing: Science, Ethics and Governance. The National Acadamies Press, Washington, DC

Nerlich B (2017) Designer babies? Not again! Making Science Public. http://blogs. nottingham.ac.uk/makingsciencepublic/2017/08/02/designer-babies-not/. Accessed 25 April 2019

Nicol D, Eckstein L, Morrison M, Sherkow JS, Otlowski M, Whitton T et al. (2017) Key challenges in bringing CRISPR-mediated somatic cell therapy into the clinic. Genome Med 9(85). https://doi.org/10.1186/s13073-017-0475-4

Nuffield Council on Bioethics (2016) Genome editing: an ethical review. Nuffield Council on Bioethics, London

Parthasarathy S (2017) Patent Politics: Life forms, markets, and the public interest in the United States and Europe. The University of Chicago Press, Chicago

Petersen A, Munsie M, Tanner C, MacGregor C, Brophy J (2017) Stem cell tourism and the political economy of hope. Palgrave Macmillan, London

Pew (2016) U.S. Public Wary of Biomedical Technologies to 'Enhance' Human Abilities. Pew Research Center, Science and Society. https://www. pewresearch.org/science/2016/07/26/u-s-public-wary-of-biomedicaltechnologies-to-enhance-human-abilities/. Accessed 4 Aug 2019

Rajan KS (2006) Biocapital: the constitution of postgenomic life. Duke University Press, Durham, NC

Regalado A (2018a) CRISPR inventor Feng Zhang calls for moratorium on geneedited babies. MIT Technology Review. https://www.technologyreview.com/s/ 612465/crispr-inventor-feng-zhang-calls-for-moratorium-on-baby-making/. Accessed 26 Nov 2019

Regalado A (2018b) EXCLUSIVE: Chinese scientists are creating CRISPR babies. MIT Technology Review. https://www.technologyreview.com/s/612458/ exclusive-chinese-scientists-are-creating-crispr-babies/. Accessed 25 Nov 2019

Regalado A (2018c) Rogue Chinese CRISPR scientist cited US report as his green light. MIT Technology Review. Rogue Chinese CRISPR scientist cited US report as his green light. Accessed 15 Aug 2019

Rowland R (1992) Living laboratories: women and reproductive technologies. Indiana University Press, Bloomington

Rosemann A, Balen A, Nerlich B, Hauskeller C, Sleeboom-Faulkner M, Hartley S et al. (2019) Heritable genome editing in a global context: national and international policy challenges. Hastings Cent Rep 49(3):30-42

Savulescu J (2007) In defence of procreative beneficience. J Med Ethics 33 (5):284-288
Simis MJ, Madden H, Cacciatore MA, Yeo SK (2016) The lure of rationality: why does the deficit model persist in science communication? Public Underst Sci 25(4):400-414

Skloot R (2011) The immortal life of Henrietta Lacks. Broadway Books, New York Smits M (2006) Taming monsters: the cultural domestication of new technology. Technol Soc 28(4):489-504

Spar DL (2006) The baby business: how money, science and politics drive the commerce of conception. Harvard Business School Press, Boston

United States President's Commission for the Study of Ethical Problems in Medicine and Biomedical and Behavioral Research (1982) Splicing life: a report on the social and ethical issues of genetic engineering with human beings. The Commission, Washington, DC

Van Hoof W, Pennings G (2011) Extraterritoriality for cross-border reproductive care: should states act against citizens travelling abroad for illegal infertility treatment? Reprod BioMed Online 23(5):546-554

Waldby C, Mitchell R (2006) Tissue economies: blood, organs and cell lines in late capitalism. Duke University Press, Durham

Waldby C (2008) Oocyte markets: women's reproductive work in embryonic stem cell research. New Genet Soc 27(1):19-31

Warnock M (1985) A question of life: the Warnock report on human fertilisation and embryology. Basil Blackwell, New York

Whittaker A (2011) Cross-border assisted reproduction care in Asia: implications for access, equity and regulations. Reprod Health Matters 19(37):107-116

Wipperman A, Campos M (2016) Genome editing technologies: the patient perspective. Genetic Alliance UK, London

Wynne B (2001) Creating public alienation: expert cultures of risk and ethics on GMOs. Sci Cult 10(4):445-481

\section{Competing interests}

The authors declare no competing interests.

\section{Additional information}

Correspondence and requests for materials should be addressed to M.M. or S.d.S.

Reprints and permission information is available online at http://www.nature.com/ reprints

Publisher's note Springer Nature remains neutral with regard to jurisdictional claims in published maps and institutional affiliations.

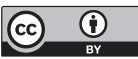

Open Access This article is licensed under a Creative Commons Attribution 4.0 International License, which permits use, sharing, adaptation, distribution and reproduction in any medium or format, as long as you give appropriate credit to the original author(s) and the source, provide a link to the Creative Commons license, and indicate if changes were made. The images or other third party material in this article are included in the article's Creative Commons license, unless indicated otherwise in a credit line to the material. If material is not included in the article's Creative Commons license and your intended use is not permitted by statutory regulation or exceeds the permitted use, you will need to obtain permission directly from the copyright holder. To view a copy of this license, visit http://creativecommons.org/ licenses/by/4.0/

(C) The Author(s) 2019 